\title{
Evaluation of chitosan-GP hydrogel biocompatibility in osteochondral defects: an experimental approach
}

\author{
Edivaldo AN Martins' ${ }^{1}$, Yara M Michelacci ${ }^{2 *}$, Raquel YA Baccarin ${ }^{3}$, Bruno Cogliati ${ }^{4}$ and Luis CLC Silva ${ }^{1}$
}

\begin{abstract}
Background: Articular cartilage, because of its avascular nature, has little capacity for spontaneous healing, and tissue engineering approaches, employing different biomaterials and cells, are under development. Among the investigated biomaterials are the chitosan-based hydrogels. Although thoroughly studied in other mammalian species, studies are scarce in equines. So, the aim of the present study was to investigate the biocompatibility of chitosan-GP in horse joints submitted to high mechanical loads.

Results: An osteochondral defect was created by arthroscopy in the medial surface of lateral trochlea of talus of left or right leg, randomly selected, from six healthy geldings. The defect was filled up with chitosan-GP. The contralateral joint received an identical defect with no implant. The chondral fragment removed to produce the defect was collected, processed and used as the "Initial" sample (normal cartilage) for histology, immunohistochemistry, and metabolic labelling of PGs. After 180 days, the repair tissues were collected, and also analyzed. At the end of the experiment (180 days after lesion), the total number of cells per field in repair tissues was equal to control, and macrophages and polymorphonuclear cells were not detected, suggesting that no significant inflammation was present. These cells were able to synthesize type II collagen and proteoglycans (PGs). Nevertheless, the cell population in these tissues, both in presence of chitosan-GP and in untreated controls, were heterogeneous, with a lower proportion of type II collagen-positives cells and some with a fibroblastic aspect. Moreover, the PGs synthesized in repair tissues formed in presence or absence of chitosan-GP were similar to those of normal cartilage. However, the chitosan-GP treated tissue had an disorganized appearance, and blood vessels were present.

Conclusions: Implanted chitosan-GP did not evoke an important inflammatory reaction, and permitted cell growth. These cells were able to synthesize type II collagen and PGs similar to those synthesized in normal cartilage and in healing tissue without implant, indicating its chondrocyte nature.
\end{abstract}

Keywords: Chitosan-GP, Cartilage, Proteoglycan, Type II collagen, Equine joint, Biocompatibility, Scaffold

\section{Background}

Injuries to articular cartilage are common, and may cause pain, disability, impairment, and early retirement of athletes. Once damaged, articular cartilage has very little capacity for spontaneous healing, and many repair techniques have been proposed over the last decades. However, repair of articular cartilage by traditional methods is challenging, due to its avascular nature and lack of a significant population of progenitor cells. For this reason,

\footnotetext{
* Correspondence: yara.bioq@epm.br

${ }^{2}$ Departamento de Bioquímica, Escola Paulista de Medicina, UNIFESP, Rua

Três de Maio, 100, 04044-020 São Paulo, SP, Brazil

Full list of author information is available at the end of the article
}

tissue engineering approaches, employing cells to in situ regenerate articular cartilage, are under development [1-3].

Both fully differentiated chondrocytes and progenitor cells (mesenchymal stem cells) have been used to produce hyaline-like cartilage $[4,5]$. Nevertheless, the strategies of cell implantation within the joint also poses challenges: a fluid environment, strong shear forces, mechanical loads, and stiff, irregular and often bleeding surfaces not easily amenable to insertion of biomaterials. Furthermore, the biomaterials to be used as cell-delivery vehicles must meet stringent requirements in that the material should be non-toxic, non-immunogenic, and must either integrate with the repair tissue or degrade 
without generating toxic by-products or leaving gaps, debris or fissures in the tissue [6]. The ideal scaffold should mimic the naturally occurring environment in the articular cartilage extracellular matrix (ECM), allowing chondrocyte proliferation and synthesis of cartilage ECM, which is composed by a dense network of collagen fibers [7], proteoglycans (PGs), and other proteins [8].

PGs are composed by a protein core with glycosaminoglycan (GAG) side chains. GAGs, in turn, are heteropolysaccharides constituted by repeating disaccharide units formed by a hexosamine (glucosamine or galactosamine) and a non-nitrogen monosaccharide (uronic acid or galactose). Most GAGs are sulfated in different degrees and positions, and both the carboxyl and the sulfate groups contribute to its polyanionic nature. The main cartilage matrix PG is aggrecan, a high molecular weight PG of the hyalectan family, composed by a $\sim 200 \mathrm{kDa}$ core protein substituted with $\sim 100$ chondroitin sulfate and $\sim 30$ keratan sulfate side chains. Aggrecan interacts with hyaluronic acid, forming large aggregates, which are entrapped in the collagen network, and provide cartilage its osmotic properties, giving cartilage its ability to resist compressive loads review in [9]. Other PGs, such as decorin, biglycan and fibromodulin, which are characterized by their ability to interact with collagen, are also present. They are much smaller than aggrecan, but may be present in similar molar amounts.

The structure and composition of aggrecan in articular cartilage changes when growth and calcification processes occur in the tissue, both during normal development and in diseases such as osteoarthritis and tumors $[10,11]$. Furthermore, the extracellular matrix composition, the cell density [12], and even mechanical compression [13] affect the chondrocyte phenotype and the synthesis of ECM components. Thus, the composition of any biomaterial used as in cartilage regeneration procedures is very important.

A wide array of matrices or hydrogels have been used as biomaterials, including proteins (collagen and fibrin), polysaccharides (agarose, alginate, hyaluronic acid and chitosan), and polymers (polyethylene glycol, poly-lactic acid) [7]. Chitosan-based hydrogels are promising due to their structural analogy to GAGs.

Chitosan is a partially deacetylated derivative of chitin, isolated from arthropod exoskeleton [14]. It is a linear polysaccharide consisting of $\beta$ (1-4) linked D-glucosamine residues, with a variable number of randomly located $\mathrm{N}$-acetyl-glucosamine residues. Chitosan is a semicrystalline polymer, and the degree of crystallinity is a function of the deacetylation level. Because of its structure, chitosan is normally insoluble in aqueous solutions above $\mathrm{pH}$ 7, but, in dilute acids, the free amino groups are protonated and the molecule becomes fully soluble below pH 5 [15].
Many chemical derivatizations of chitosan have been used to promote new biological activities and to modify its mechanical properties $[16,17]$. The addition of polyol salts such as sodium glycerol phosphate to chitosan creates chitosan-glycerol phosphate (GP), a thermosensitive hydrogel that forms a viscous liquid at room temperature or below, and converts to a semisolid gel at body temperature [18-20]. Chitosan-based vehicle can be loaded into an osteochondral defect in living joints as a viscous liquid, and upon solidification, adheres to bone and to cartilage [15]. Furthermore, previous studies have shown that chitosan is hemostatic [21], and stimulates revascularization of the wound and connective tissue repair [22].

The aim of the present study was to investigate the biocompatibility of a chitosan-based hydrogel - chitosanGP - in horses, specifically in joints submitted to high mechanical load. If proved biocompatible in horses, chitosan-GP could be used, in the future, as a vehicle for cell and/or drug delivery as an adjuvant to promote cartilage regeneration.

\section{Methods}

\section{Animals}

The present work was approved by the Ethical Committee of Universidade de São Paulo - USP (1245/2007), and was carried out in accordance with USP guidelines, and also in accordance with EC Directive 86/609/EEC for animal experiments http://ec.europa.eu/environment/chemicals/lab_ animals/legislation_en.htm.

Six Mangalarga healthy geldings, 3 years old, 300$315 \mathrm{~kg}$ body weight (average $=307 \mathrm{~kg}$ ), from the USP research herd, were used in the present study. Clinical, laboratorial, radiographic and ultrassonographic exams were performed before inclusion in the experimental group, and all were considered normal. The animals were housed in single $12 \mathrm{~m}^{2}$ boxes $(3 \times 4 \mathrm{~m})$ and fed pellets ( $1 \%$ of the animal body weight), coast cross hay and water ad libitum.

\section{Preparation and application of chitosan-glycerol phosphate gel}

Chitosan-GP gel was obtained as described by Chenite et al. [18]. In brief, chitosan ${ }^{\mathrm{a}}$ of $310-375 \mathrm{kDa}$ (based on the viscosity range of $800-2000 \mathrm{mPaS}$ ) deacetylation grade $>75 \%$ ( $200 \mathrm{mg}$ ), was solubilised in $0.1 \mathrm{M}$ hydrochloric acid $(9 \mathrm{~mL})$. To this solution, $560 \mathrm{mg}$ of sodium glycerol phosphate ${ }^{\mathrm{b}}$ dissolved in $1 \mathrm{~mL}$ of water were added, slowly and under continuous agitation. A whitish gel resulted, which was transferred to glass tubes, sterilized in autoclave, and stored for no more than $24 \mathrm{~h}$ at room temperature.

To test the biocompatibility of chitosan-GP, an osteochondral defect $(1 \mathrm{~cm}$ diameter and $0.5 \mathrm{~cm}$ deep) was created by arthroscopy in the medial surface of lateral 
trochlea of talus, in left or right leg, randomly selected. A cartilage sample was collected with Ferris-Smith rongeous, and used as "Initial sample". Afterwards, a depression was created in the subjacent bone using a bone burr attached to a power shaving system. This osteochondral defect was filled up with chitosan-GP gel $(\sim 0.5 \mathrm{~mL})$. The gel was delivered using an insulin syringe $(1 \mathrm{~mL})$, with cut end. For gel delivery, fluid infusion was replaced by $\mathrm{CO}_{2}$, using a laparoscopic insuflattor calibrated to maintain $30 \mathrm{mmHg}$ until the end of the procedure, allowing gel retention in the defect. The contralateral joint received an identical defect with no implant, and served as matched control.

After arthroscopy, all horses received intravenous amikacin, $15 \mathrm{mg} / \mathrm{kg}$, and phenylbutazone, $4.4 \mathrm{mg} / \mathrm{kg}$, every $24 \mathrm{~h}$, for three days. At the end of the experimental period (day 180), arthroscopy was repeated for the collection of the "Final" samples, and the same antibiotic and anti-inflammatory therapy was repeated.

\section{Cartilage analysis}

The cartilage samples collected during arthroscopy were cut in three fragments, used for: (1) histology; (2) immunohistochemistry for type II collagen; (3) metabolic labelling and analysis of proteoglycans (PGs).

\section{Histology}

For histology, the tissue fragments were fixed in Methacarn (60\% methanol, 30\% chloroform, 10\% acetic acid) for $6 \mathrm{~h}$, and then transferred to $90 \%$ ethanol. The tissues were dehydrated, embedded in paraffin, and cut in $3 \mu \mathrm{m}$ sections. These sections were transferred to silanecoated microscope slides, dewaxed and stained with hematoxylin and eosin ( $\mathrm{H} \& \mathrm{E})$.

\section{Immunofluorescence of type II collagen}

For immunofluorescence labelling, the tissue fragments were fixed as above described, dehydrated, embedded in paraffin, and cut in $5 \mu \mathrm{m}$ sections. These sections were transferred to silane-coated microscope slides and dewaxed. Antigen retrieval was performed by incubation with $0.4 \%$ pepsin (Sigma) in $0.5 \mathrm{M}$ acetic acid, $30 \mathrm{~min}$, $37^{\circ} \mathrm{C}$. After washing with phosphate buffering saline (PBS), polyclonal anti-type II collagen antibody ${ }^{\mathrm{c}}$ was added as primary antibody $(100 \mu \mathrm{L}), 1: 50$ in blocking solution containing $1 \%$ bovine serum albumin, $\mathrm{BSA}^{\mathrm{d}}, 0.3 \%$ Tween 20 and $0.1 \%$ sodium azide. This antibody binds both type II mature collagen and procollagen. After overnight incubation at $4^{\circ} \mathrm{C}$, the slides were washed with PBS and incubated with secondary antibody swine antirabbit IgG, FITC-conjugated ${ }^{\mathrm{e}}$, diluted 1:100 in PBS. After $90 \mathrm{~min}$ incubation in moist and dark chamber, the sections were counterstained with propidium iodide (1:1000), which stains cell nucleus in red. Slides were mounted in Vectashield to preserve fluorescence ${ }^{\mathrm{f}}$, and sealed with clear nail polish. Negative controls consisted of cartilage sections that had not been incubated with primary antibody.

Images were obtained with a Nikon E-800 fluorescence microscope, 400 times magnification, and morphometric analysis was performed using the software Image ProPlus 4.5. The evaluation consisted of counting 100 cells per sample, in random selected fields, following basic stereological principles. The results are expressed in percentage of type II collagen -positive cells.

\section{Metabolic labelling and analysis of proteoglycans}

For metabolic labelling of PGs, the cartilage fragment ( 100 mg) was transferred to a sterile bottle containing $10 \mathrm{~mL}$ of $\mathrm{F} 12$ culture medium containing penicillin $(10.000 \mathrm{U})$, streptomycin $(100 \mathrm{mg})$ and ${ }^{35} \mathrm{~S}$-sulfate ${ }^{\mathrm{g}}$ $(100 \mu \mathrm{Ci})$. The tissue explants were transferred to Dept. of Biochemistry, Escola Paulista de Medicina, and maintained at $37^{\circ} \mathrm{C}$ in a $2.5 \% \mathrm{CO}_{2}$ atmosphere. After $24 \mathrm{~h}$, the medium and the tissue explants were collected and processed separately.

\section{Extraction of ${ }^{35} \mathrm{~S}-\mathrm{PG}$ from tissue explants}

From the conditioned culture medium, the PGs were precipitated by careful and slow addition of methanol (3 volumes), and after $18 \mathrm{~h}$ at $-20^{\circ} \mathrm{C}$, the precipitate formed was collected by centrifugation, dried and resuspended in $100 \mu \mathrm{L}$ of water for analysis.

From the tissue explants, ${ }^{35} \mathrm{~S}-\mathrm{PG}$ extraction was performed as previously described [23-25]. Each tissue explant was carefully cut in small pieces, and incubated with $1 \mathrm{~mL}$ of $4 \mathrm{M}$ guanidine hydrochloride $(\mathrm{GuHCl})^{\mathrm{h}}$ in $0.05 \mathrm{M}$ sodium acetate buffer, $\mathrm{pH}$ 6.5, containing protease inhibitors $(0.1 \mathrm{M} \epsilon$-aminocaproic acid, $6.5 \mathrm{mM}$ benzamidine, $5.5 \mathrm{mM}$ iodocetamide and $0.1 \mathrm{M}$ phenylmethylsulfonyl fluoride). After overnight incubation at $4^{\circ} \mathrm{C}$ under agitation, debris was collected by centrifugation, and the extraction process was repeated with $0.5 \mathrm{~mL}$ of the $4 \mathrm{M}$ $\mathrm{GuHCl}$. After $24 \mathrm{~h}$, debris was removed by centrifugation and both supernatants were combined. PGs were precipitated by slow addition of methanol (3 volumes), under agitation. Subsequently, the precipitates formed after $18 \mathrm{~h}$ at $-20^{\circ} \mathrm{C}$ were collected by centrifugation $(3000 \times \mathrm{g}$, $20 \mathrm{~min}$ ), washed with $80 \%$ methanol, and vacuum dried. The dried material was resuspended in water $(100 \mu \mathrm{L})$, and the solutions were stored at $-20^{\circ} \mathrm{C}$.

\section{Identification and quantification of ${ }^{35} \mathrm{~S}-\mathrm{PGs}$}

The ${ }^{35}$ S-PG samples were analyzed by a combination of agarose gel electrophoresis and enzymatic degradation with proteases and specific GAG lyases, as already described [26]. Aliquots of the ${ }^{35} \mathrm{~S}-\mathrm{PG}$-containing solutions (5 $\mu$ l containing $0.5-5 \mu \mathrm{g}$ ) were submitted to agarose gel 
electrophoresis in $0.05 \mathrm{M}$ 1,3-diaminopropane-acetate buffer (PDA), pH 9 [27]. After fixation with cetyltrimethylammonium bromide and Toluidine Blue staining, PGs were quantified by densitometry of the gel slabs ${ }^{i}$. The ${ }^{35} \mathrm{~S}$-sulfate labelled compounds were visualized by exposure of the gel slabs to a Packard Cyclone TM Storage Phosphor System by 24 hours. For quantification, the bands containing radiolabelled compounds were scrapped from the gel slabs and counted in a liquid scintillation spectrophotometer, using Ultima Gold LSCCocktail ${ }^{j}$. The quantitative results were always corrected for ${ }^{35} \mathrm{~S}$-decay.

\section{Statistical analysis}

Data were evaluated for normality by the KolmogorovSmirnov test. Afterwards, the Analysis of Variance was used to compare the groups and effect of treatments. To contrast between mean values the Tukey-Kramer test was used. For non-parametric values, Kruskal-Wallis test was used to compare initial and final results, while Mann-Whitney test was used to compare the chitosanGP-treated joints to the untreated. The GraphPad Instat 3 was used to perform the statistical analysis.

\section{Results}

\section{Histology and immunohistochemistry of type II collagen with fluorescence labelling}

Gross observation revealed that at the beginning of experiment, the articular cartilage was normal with smooth surface. At the end of experimental period (day 180), a slight depression was easily detected by arthroscopy as the lesion was observed. The surface was also smooth and cartilage-like. Histological images of the initial chondral fragment obtained by arthroscopy is shown in Figure 1 (A and B). Chondrocytes are embedded in abundant avascular ECM of homogeneous appearance upon HE staining. Figure 1-C shows that, 180 days after osteochondral injury (Final), the chitosan-GP treated tissue had an abnormal, disorganized appearance. The cells were also embedded in abundant ECM, but now blood vessels were present. In both healing tissues, some cells presented a "fibroblastic" morphology. Possibly, they are mesenchymal cells that could differenciate into either chondrocytes or fibroblasts. The total number of cells per field did not change, and macrophages and polymorphonuclear cells were not detected, suggesting that no significant inflammation was present in the "Final" samples (180 days). Similar results were obtained for all animals, and Figure 1 shows representative samples of each group.

Immunofluorescence for type II collagen was performed as described in Methods, and the percentage of type II collagen-positive cells was measured (Figure 2). Although the matrix was also labelled, our focus was the newly synthesized pro-collagen present in the cells. In normal cartilage, about $70 \%$ of the cartilage cells were type II collagen-positive, while in healing tissues this number was much lower ( 40\%). Nevertheless, there was no difference between healing tissues formed in presence or absence of chitosan-GP.

\section{Proteoglycans}

Representative agarose gel electrophoresis of ${ }^{35} \mathrm{~S}-\mathrm{PG}$ extracted from cartilage explants $(\mathrm{T})$ and conditioned culture medium $(\mathrm{M})$, from normal tissues obtained at the beginning of experiment (Initial), and repair tissues collected at the end of experimental period (Final), from chitosan-GP-treated lesions (Chitosan-GP) and untreated lesions (No treatment) is shown in Figure 3. Both Toluidine Blue staining and radioautograms are shown. The radioactive band corresponded to the Toluidine Blue stained PGs, indicating that PGs were the main ${ }^{35} \mathrm{~S}$-sulfate labelled compounds. Intact PGs migrated near heparan sulfate (free GAG), but upon digestion with proteases (not shown), only chondroitin sulfate free chains appeared, indication that most of the ${ }^{35} \mathrm{~S}-\mathrm{PG}$ synthesized are chondroitin sulfate-PGs.

Figure 4 shows the quantitative data for total PGs (stained by Toluidine Blue and quantified by densitometry) and newly synthesized, labelled PGs ( $\left.{ }^{35} \mathrm{~S}-\mathrm{PGs}\right)$. In all cases, most of the ${ }^{35} \mathrm{~S}-\mathrm{PG}$ s were found in the tissue explants, with only $10-12 \%$ of total ${ }^{35}$ S-PGs in culture medium of normal tissues (Initial). Although both the total amounts of PGs (Figure 4-A) and ${ }^{35}$ S-PGs (Figure 4-B) were lower in healing tissues, a higher proportion (30-33\%) was found in culture media (Figure 4-C), suggesting that the extracellular matrix was less dense than in the normal tissue. The healing tissues contained also lower amounts of PGs, detected both by Toluidine Blue staining and radioactivity.

The PG concentration in the culture medium was very low, undetectable by Toluidine Blue staining. For this reason, it was impossible to determine the specific activities of PGs secreted to the culture medium. So, only tissue explants were considered to measure specific activities. In healing tissues, although the amounts of PGs were lower than normal, the specific activities were increased (Figure 5), indicating higher synthesis rates. The specific activities were even higher in the chitosan-GP-treated lesions. Nevertheless, individual variation did occur, possibly due to different numbers of PG-synthesizing cells in each sample.

\section{Discussion}

Much of the potential of chitosan as a biomaterial is thought to come from its cationic nature and high charge density. Because the chitosan charge density is $\mathrm{pH}$ dependent, transfer of chitosan-polyanion complexes to 


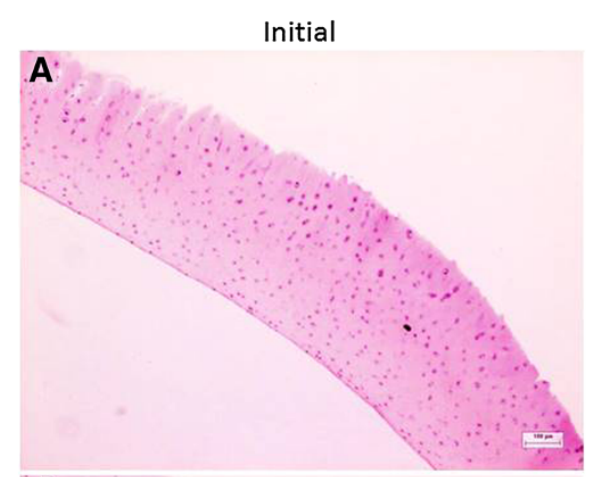

B

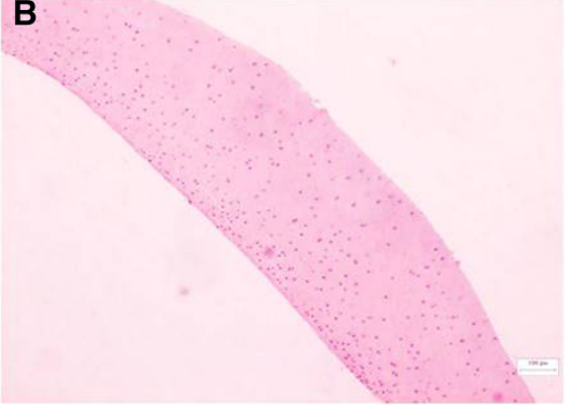

Figure 1 Optical microscopy of normal articular cartilage (A and B, Initial) collected at the first arthroscopy to produce the osteochondral defect, and the healing tissues (Final, day 180) formed in presence (C) or absence of chitosan-GP (D). Tissue samples collected during surgery were fixed in Methacarn, transferred to 90\% ethanol, dehydrated, embedded in paraffin and cut in $3 \mu \mathrm{m}$ sections. These sections were transferred to silane-coated slides, dewaxed, and stained with hematoxylin and eosin (H \& E).

physiological pH can result in dissociation of the immobilized polyanion, and this could be used for local delivery of biologically active molecules [28]. Furthermore, the Nacetylglucosamine moiety of chitosan is also found in some GAGs, such as hyaluronic acid, heparan suphate and heparin, giving these molecules a certain degree of structural analogy. It is possible that chitosan might present some of the GAG biological activities, such as the

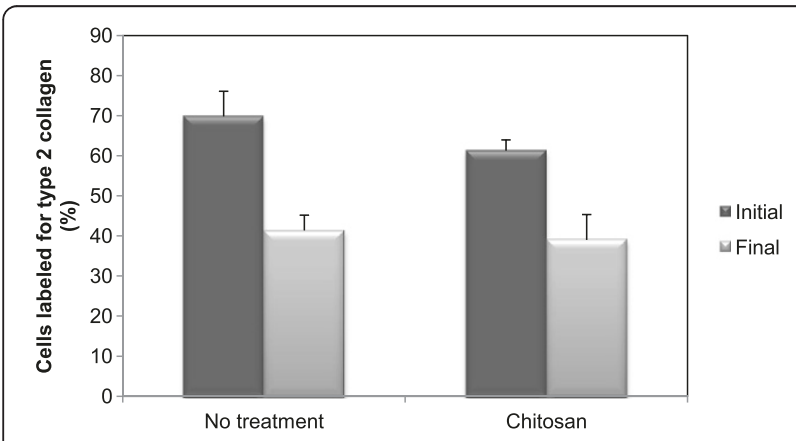

Figure 2 Percentage of cells stained for type II collagen in normal articular cartilage (Initial) and in healing tissues formed in presence or absence of chitosan-GP. Cells were counted under fluorescence microscope, and the relative number of type II collagen-positive cells (green and yellow cells) is given (as percent). Brackets indicate differences statistically significant $(P<0.05)$. ability to bind growth factors, receptors and adhesion molecules. However, Hamilton et al. claim that other properties may be important in biological performance of chitosan [29].

Many authors propose chitosan-based biomaterials for cartilage tissue regeneration, but different chitosan formulations are used. The chitosan molecular weight may range from as little as $10 \mathrm{kDa}$ to over $1,000 \mathrm{kDa}$, while the deacetylation degree may oscillate from $50 \%$ to $95 \%$ [30]. High molecular weight and high deacetylation degrees are related to lower material degradation, while the deacetylation degree is also related with cell adhesion and proliferation. In the present paper, we choose to employ an intermediate molecular weight, and a 310$375 \mathrm{kDa}$ chitosan, with 75\% deacetylation was used.

The chitosan primary amino groups are reactive and provide a mechanism for side group attachment using mild reaction conditions. The general effect of addition of a side group is to disrupt the crystalline structure of chitosan and hence increase the amorphous fraction, generating a material with lower stiffness and altered solubility. Chitosan-GP is one such compound [19], having the additional benefit of forming a thermosensitive hydrogel that forms a viscous liquid at room temperature, and converts to a semisolid gel at body temperature, making easier its application in osteochondral defects. There 


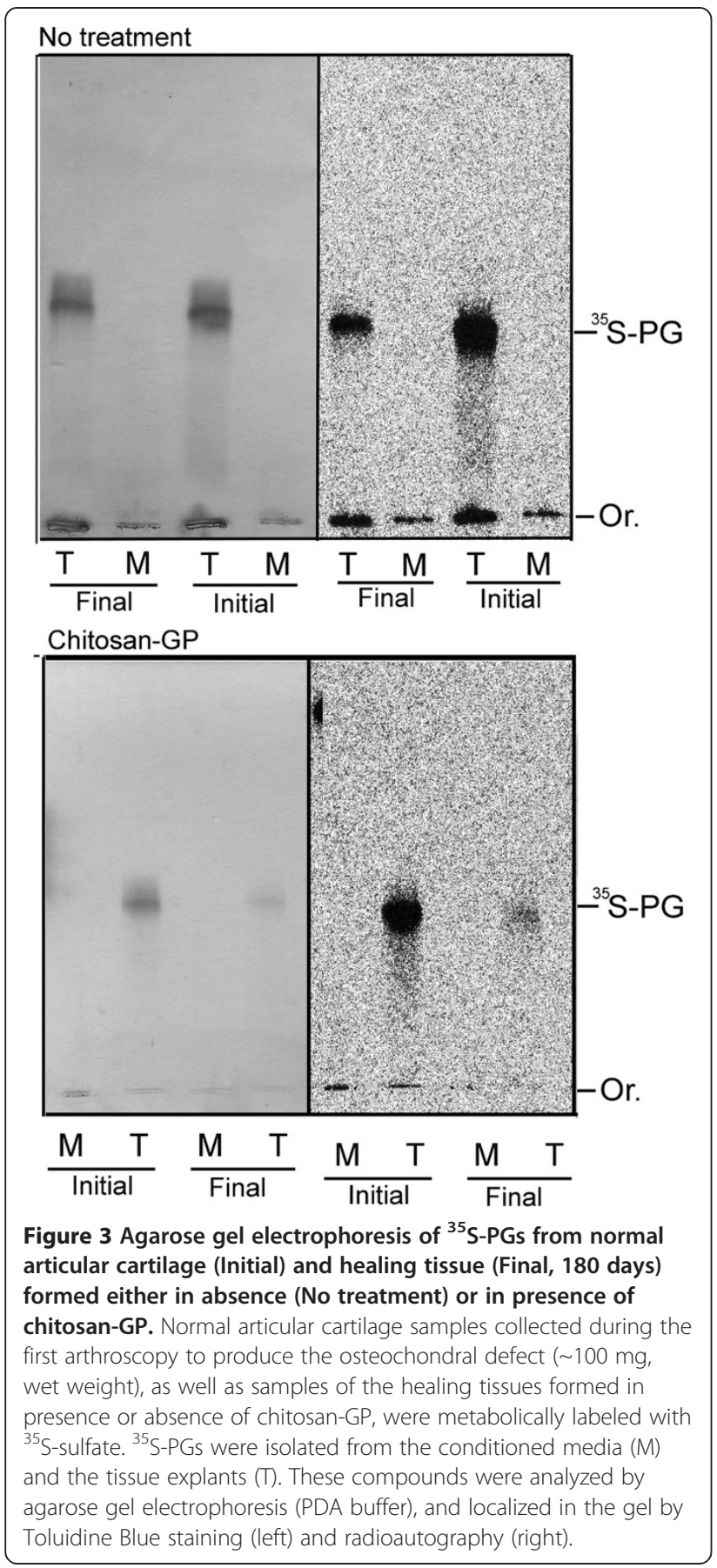

are strong evidences that the gelation in the chitosan-GP system induced by heating is the result of a progressive and homogeneous reduction of the ionization degree of chitosan [31].

Other carbohydrate-based biomaterials, such as polylactic/polyglycolic acids, agarose, and alginate, have been used, but most of them, in contrast to chitosan, give strong foreign body reactions review in [32].

Although thoroughly studied in humans and in experimental models reviews in $[1,14]$, only a few reports on the use of chitosan-based biomaterials in equines have been published [33], and while the body response to various chitosan-based implants has been studied in other species [30,34], there are scarce studies in horses. In general, studies in other species have revealed that chitosan-based materials are biocompatible and evoke minimal foreign body reaction. Chitosan, chitosan fragments, and chitin have been shown to have short-term stimulatory effects on the immune system [35-37], which may play a role in inducing local cell proliferation and ultimately integration of the implanted material within the host tissues. In the rabbit, it was shown that less adverse tissue response occurred with better biodegradable samples, of low molecular weight chitosan and low deacetylation degree (83\%) [30]. With high molecular weight chitosan (350-510 kDa) or high deacetylation degree (91\%), however, Abarrategi et al. described synovial membrane inflammation, no cartilage formation, no material degradation, and nonsmooth surface [30]. In contrast, our findings in horses, using chitosan-GP of 310$375 \mathrm{kDa}$ and $75 \%$ deacetylation, revealed smooth surface, with a good host integration of healing tissue, and no evidence of chronic inflammation in any of our experimental animals. Blood vessels were observed in repair tissues formed in presence of chitosan-GP, as were also reported by others, who concluded that chitosan induces a transient vascularization when implanted in cartilage [30]. In a rabbit model, chitosan-GP/blood implants induce angiogenesis and subchondral bone remodeling. These observations suggest that chitosan-GP/blood implants leads to a porous subchondral bone structure with well vascularized marrow cavities, that could promote more effective cartilage repair [38].

Histology of the repair tissue did not show any changes in the number of cells per field, and macrophages and polymorphonuclear cells were not detected, indicating that the implanted chitosan-GP did not evoke an important inflammatory reaction, while permitting cell proliferation. These cells were able to synthesize type II collagen and PGs, suggesting its "chondrocyte" nature. Nevertheless, the cell population in healing tissues, both in presence of chitosan-GP and in untreated controls, were heterogeneous: only $\sim 40 \%$ of the cells were type II collagenpositives and some presented a fibroblastic aspect under light microscopy. A histological scoring system, as well as staining with Safranin-O, Toluidine Blue, and use of polarized microscopy for collagen could be useful to further characterize the healing tissues. However, tissue fragments were differently processed for histology, immunofluorescence, and proteoglycan synthesis under tissue culture conditions, leaving not enough material left for the above mentioned analyses.

Moreover, the PGs synthesized in presence of chitosan-GP were similar to those synthesized in healing tissue without 

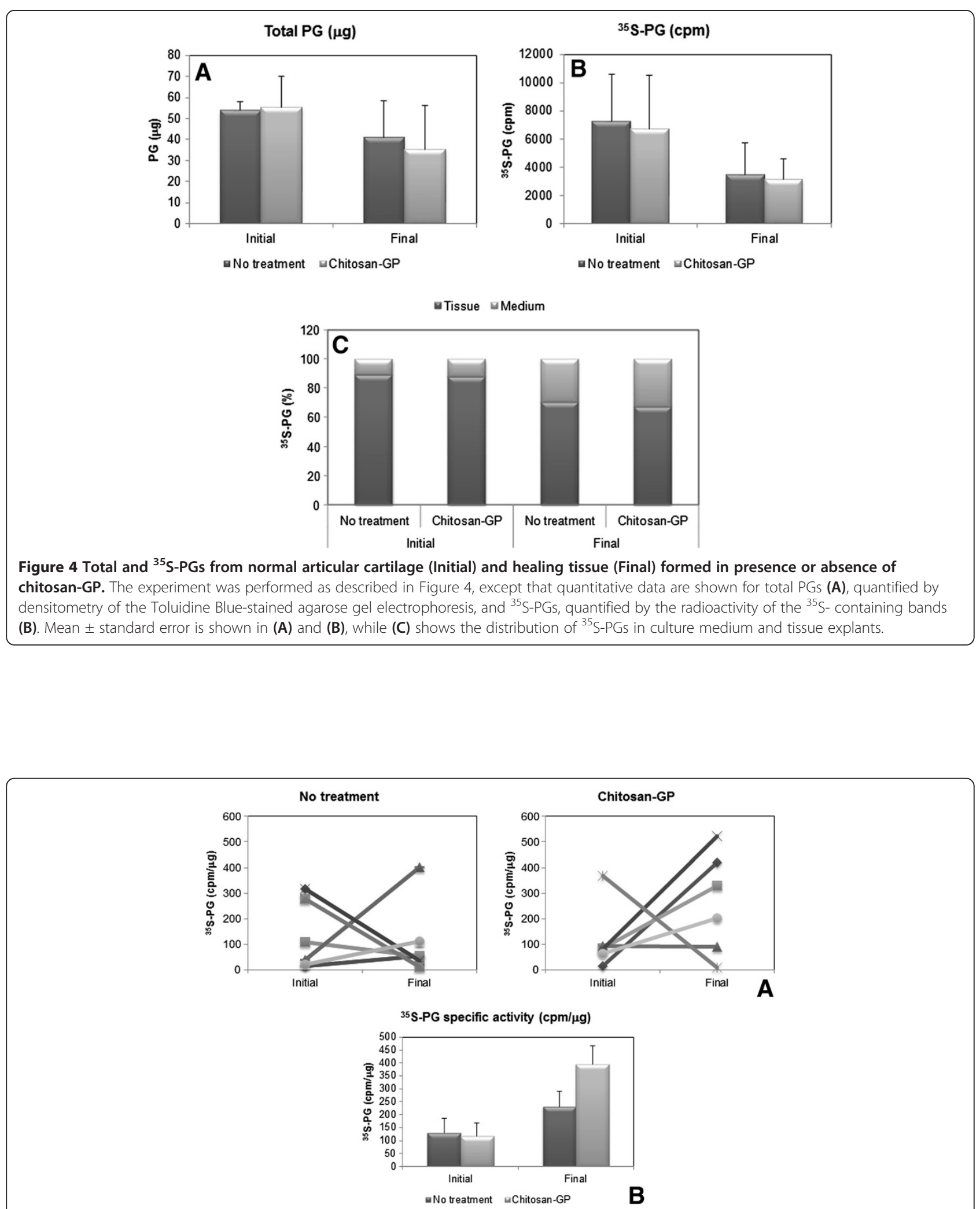

Figure 5 Individual and mean ${ }^{35} \mathrm{~S}$-PGs specific activities from normal articular cartilage (Initial) and healing tissue (Final) formed in presence or absence of chitosan-GP. The experiment was performed as described in Figure 3, except that only the PGs extracted from tissue explants were considered. Specific activity is expressed as $\mathrm{cpm} / \mu \mathrm{g}$ of tissue protein. Individual paired results, and mean \pm standard error are shown in (A) and (B), respectively. 
implant, and also to normal cartilage, except that higher proportions of PGs were found in the culture medium of repair tissues. This suggests that the extracellular matrix of the newly synthesized tissue is less dense, in agreement with the findings on type II collagen labelling (see Figures 2 and 4). Chitosan-GP in horses did not increase the PG synthesis rate, although the specific activity of ${ }^{35} \mathrm{~S}$-PGs was slightly increased (difference not statistically significant, Figure 5). This is also in agreement with previously reported data on chondrocytes cultured on chitosanchondroitin sulphate complexes [14], which produced equal to control amounts of PGs and type II collagen. Nevertheless, the specific activity of ${ }^{35}$ S-PGs varied among different animals. This is possibly due to the variations in the number of PG-synthesizing cells in each sample.

It is worth mentioning that these results are related to the osteochondral defect model here employed. In the equine species, the relevance of this model resides in the high prevalence of osteochondral lesions, both acquired or inherited [39,40]. Furthermore, the choice of the depth of the articular cartilage defect has great impact in the tissue response. Osteochondral defects, as employed in the present study, span the entire depth of articular cartilage and penetrate subchondral bone marrow, creating an access to blood cells, macrophages, mesenchymal cells and soluble factors [41]. Osteochondral defects exhibited a rapid cellular response, as opposed to chondral defects, which exhibited a minor healing response, with little cell infiltrates [42]. It is also important to mention that both models of defect design - chondral and osteochondral - are relevant for equines $[43,44]$ as well as for other species $[32,41]$, and the choice to use one or the other must be made judiciously.

\section{Conclusions}

Despite extensive research on articular cartilage healing during the last decades, successful repair of damaged cartilage has not been fully achieved. While many new techniques have recently emerged and demonstrated promising results in experimental models, few have exhibited long-term clinical efficacy. Tissue engineering has recently emerged as an interdisciplinary topic, using in vitro cultured cells and tissues, together with artificial implants. Our findings on chitosan-GP suggest that it may be well suitable as a biomaterial for cartilage repair [45] that could also be used in drug and/or cell delivery [46]. Future studies using in vitro cultured chondrocytes will explore this potential.

\section{Endnotes}

${ }^{\mathrm{a} C}$ Cat \#9012-76-4, 419419, Sigma-Aldrich, MO, USA;

${ }^{\mathrm{b}}$ Cat \#55076-41-1, Sigma-Aldrich, MO, USA;

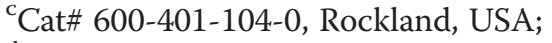

${ }^{\mathrm{d} C a t \# ~ A 9647, ~ S i g m a, ~ M O, ~ U S A ; ~}$
${ }^{\mathrm{e}}$ Dako, Carpinteria, CA, USA;

${ }^{\mathrm{f}}$ Vector Laboratories, Inc, Burlingame, CA, USA;

${ }^{g}$ IPEN-CNEM, São Paulo, SP, Brazil;

${ }^{\text {h}}$ Sigma-Aldrich Chemical Co. Inc, Milwaukee, WI, USA;

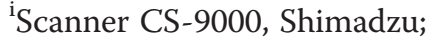

${ }^{j}$ Packard Instruments Company Inc., Downers Grove, IL, USA.

\section{Abbreviations}

ECM: Extracellular matrix; PGs: Proteoglycans; GAGs: Glycosaminoglycans;

GP: Glycerol phosphate; H \& E: Hematoxylin and eosin; PBS: Phosphate buffering saline; GuHCL: Guanidine hydrochloride; PDA: 1,3-diaminopropane-acetate.

\section{Competing interests}

The authors declare that they have no competing interests.

\section{Authors' contributions}

LCLCS designed the study and was responsible for obtaining funds. LCLCS and EANM performed all the arthroscopies. EANM and RYAB collected tissue samples and conducted the experimental analysis. RYAB performed the metabolic labelling, isolation, and characterization of proteoglycans, under the supervision of YMM, and participated in the writing and revision of the manuscript. YMM designed and supervised the studies on cartilage proteoglycans, and wrote the manuscript. BC performed the histological analysis. All authors read and approved the final manuscript.

\section{Acknowledgements}

The authors want to express their gratitude to Dr. Maria Gabriela N. Campos, Faculdade de Engenharia Química, UNICAMP, Campinas, SP, Brazil, for the preparation of chitosan-GP; to Dr. Thaís S.L. Machado, for noteworthy help in some of the experiments on proteoglycan isolation and characterization; and to Prof. Dr. Maria Lucia Z. Dagli, Departamento de Patologia Animal, FMVZ-USP, São Paulo, SP, Brazil, for histological analysis.

This research was supported by Conselho Nacional de Desenvolvimento Científico e Tecnológico (CNPq), Brasília, DF, Brazil; Fundação Coordenação de Aperfeiçoamento de Pessoal de Nível Superior (CAPES), Brasília, SP, Brazil; and Fundação de Amparo à Pesquisa do Estado de São Paulo (FAPESP), São Paulo, SP, Brazil. These sponsors did not have any influence on the study design, on the collection, analysis and interpretation of data, or on the writing of the manuscript and decision to submit for publication.

\section{Author details}

'Departamento de Cirurgia, Faculdade de Medicina Veterinária e Zootecnia, USP, São Paulo, SP, Brazil. ²Departamento de Bioquímica, Escola Paulista de Medicina, UNIFESP, Rua Três de Maio, 100, 04044-020 São Paulo, SP, Brazil.

${ }^{3}$ Departamento de Clínica Médica, Faculdade de Medicina Veterinária e Zootecnia, USP, São Paulo, SP, Brazil. ${ }^{4}$ Departamento de Patologia, Faculdade de Medicina Veterinária e Zootecnia, USP, São Paulo, SP, Brazil.

Received: 8 August 2013 Accepted: 15 August 2014

Published: 27 August 2014

\section{References}

1. Temeroff JS, Mikos AG: Review: tissue engeneering for regeneration of articular cartilage. Biomaterials 2000, 21:431-440.

2. Lynn AK, Brooks RA, Bonfield W, Rushton N: Repair of defects in articular joints. J Bone Joint Surg Am 2004, 86:1093-1099.

3. Beris AE, Lykissas MG, Papageorgiou CD, Georgoulis AD: Advances in articular cartilage repair. Injury 2005, 36:14-23.

4. Grande DA, Southerland SS, Manji R, Pate DW, Schwartz RE, Lucas PA: Repair of articular cartilage defects using mesenchymal stem cells. Tissue Eng 1995, 1:345-353.

5. Caplan Al, Correa D: The MSC: an injury drugstore. Cell Stem Cell 2011, 9:11-15.

6. Garg T, Singh O, Arora S, Murthy R: Scaffold: a novel carrier for cell and drug delivery. Crit Rev Ther Drug Carrier Syst 2012, 29:1-63.

7. Wenstrup RJ, Florer JB, Brunskill EW, Bell SM, Chervoneva I, Birk DE: Type V collagen controls the initiation of collagen fibril assembly. J Biol Chem 2004, 279:53331-53337. 
8. Martel-Pelletier J, Boileau C, Pelletier JP, Roughley PJ: Cartilage in normal and osteoarthritis conditions. Best Pract Res Clin Rheumatol 2008, 22:351-384.

9. Roughley PJ, Lee ER: Cartilage proteoglycans: structure and potential functions. Microsc Res Tech 1994, 28:385-397.

10. Michelacci YM, Mourão PAS, Laredo-Filho J, Dietrich CP: Chondroitin sulfates and proteoglycans from normal and arthrosic human cartilages. Connect Tissue Res 1979, 7:29-36.

11. Mourão PAS, Michelacci YM, Toledo OMS: Glycosaminoglycans and proteoglycans of normal and tumoral cartilages of humans and rats. Cancer Res 1979, 39:2802-2806.

12. Kate $Y$, Gospodarowicz D: Effect of exogenous extracellular matrices on proteoglycan synthesis by cultured rabbit costal chondrocytes. J Cell Biol 1985, 100:486-495

13. Pingguan-Murphy B, Lee DA, Bader DL, Knight MM: Activation of chondrocytes calcium signalling by dynamic compression is independent of number of cycles. Arch Biochem Biophys 2005, 444:45-51.

14. Francis Suh J-K, Matthew HWT: Application of chitosan-based polysaccjaride biomaterials in cartilage tissue engineering: a review. Biomaterials 2000, 21:2589-2598.

15. Hoemann CD, Sun J, Légaré A, McKee MD, Buschmann MD: Tissue engineering of cartilage using an injectable and adhesive chitosan-based cell-delivery vehicle. Osteoarthritis Cartilage 2004, 13:318-329.

16. Choa JH, Kim S-H, Park KD, Jung MC, Yang WI, Han SW, Noh JY, Lee JW: Chondrogenic differentiation of human mesenchymal stem cells using a thermosensitive poly (N-isopropylacrylamide) and water-soluble chitosan copolymer. Biomaterials 2004, 25:5743-5751.

17. Chen J-P, Cheng T-H: Thermo-responsive chitosan-graft-poly (N-isopropylacrylamide) injectable hydrogel for cultivation of chondrocytes and meniscus cells. Macromol Biosci 2006, 6:1026-1039.

18. Chenite A, Chaput C, Wang D, Combes C, Buschmann MD, Hoemann CD, Leroux JC, Atkinson BL, Binette F, Selmani A: Novel injectable neutral solutions of chitosan form biodegradable gels in situ. Biomaterials 2000, 21:2155-2161.

19. Hoemann CD, Sun J, McKee MD, Chevrier A, Rossomacha E, Rivard G-E, Hurtig M, Buschmann MD: Chitosan-glycerol phosphate/blood implants elicit hyaline cartilage repair integrated with porous subchondral bone in microdrilled rabbit defects. Osteoarthritis Cartilage 2007, 15:78-89.

20. Ngoenkam J, Faikrua A, Yasothornsrikul S, Viyoch J: Potential of an injectable chitosan/starch/beta-glycerol phosphate hydrogel for sustaining normal chondrocyte function. Int J Pharm 2010, 391:115-124.

21. Malette WG, Quigley HJ, Gaines RD, Johnson ND, Rainer WG: Chitosan: a new hemostatic. Ann Thorac Surg 1983, 36:55-58.

22. Ueno H, Nakamura F, Murakami M, Okumura M, Kadosawa T, Fujinag T: Evaluation effects of chitosan for the extracellular matrix production by fibroblasts and the growth factors production by macrophages. Biomaterials 2001, 22:2125-2130.

23. Sampaio LO, Bayliss MT, Hardingham TE, Muir H: Dermatan sulfate proteoglycan from human articular cartilage. Variation in its contents with age and structural comparison with a small chondroitin sulfate proteoglycan from pig laryngeal cartilage. Biochem J 1988, 254:757-764.

24. Berto AGA, Sampaio LO, Franco CRC, Cesar RM Jr, Michelacci YM: A comparative analysis of structure and spatial distribution of decorin in human leiomyoma and normal myometrium. Biochim Biophys Acta 2003, 1619:98-112.

25. Martins SAR, Campos MSQ, Berto AGA, Aguiar JAK, Michelacci YM: Proteoglycan synthesis by human corneal explants submitted to laser in situ keratomileusis (LASIK). Mol Vis 2007, 13:142-150.

26. de Lima CR, dos Santos-Junior JA, Nazário ACP, Michelacci YM: Changes in glycosaminoglycans and proteoglycans of normal breast and fibroadenoma during the menstrual cycle. Biochim Biophys Acta 1820, 2012:1009-1019.

27. Dietrich CP, Dietrich SMC: Eletrophoretic behaviour of acidic mucopolysaccharides in diamine buffers. Anal Biochem 1976, 70:645-647.

28. Denuziere A, Ferrier D, Damour O, Domard A: Chitosan-chondroitin sulfate and chitosan-hyaluronate polyelectrolyte complexes: biological properties. Biomaterials 1998, 19:1275-1285.

29. Hamilton V, Yuan Y, Rigney DA, Puckett AD, Ong JL, Yang Y, Elder SH, Bumgardner JD: Characterization if chitosan films and effects on fibroblast cell attachment and proliferation. J Mater Sci Mater Med 2006, $17: 469-485$
30. Abarrategi A, Lópiz-Morales Y, Ramos V, Civantos A, López-Durán L, Marco F, López-Lacomba JL: Chitosan scaffolds for osteochondral tissue regeneration. J Biomed Mater Res A 2010, 95:1132-1141.

31. Lavertu M, Filion D, Buschmann MD: Heat-induced transfer of protons from chitosan to glycerol phosphate produces chitosan precipitation and gelation. Biomacromolecules 2008, 9:640-650.

32. Hunziker EB: Articular cartilage repair: basic science and clinical progress. A review of the current status and prospects. Osteoarthritis Cartilage 2001, 10:432-463.

33. Bertolo A, Mehr M, Aebli N, Baur M, Ferguson SJ, Stoyanov JV: Influence of different commercial scaffolds on the in vitro differentiation of human mesenchymal stem cells to nucleus pulposus-like cells. Eur Spine J 2012, 21(Suppl 6):826-838.

34. Onishi $H$, Machida $Y$ : Biodegradation and distribution of water-soluble chitosan in mice. Biomaterials 1999, 20:175-182.

35. Peluso G, Petillo O, Ranieri M, Santin M, Ambrosio L, Calabro D, Avallone B, Balsamo G: Chitosan-mediated stimulation of macrophage function. Biomaterials 1994, 15:1215-1220.

36. Usami Y, Okamoto Y, Minami S, Matsuhashi A, Kumazawa NH, Tanioka S, Shigemasa $Y$ : Migration of canine neutrophils to chitin and chitosan. J Vet Med Sci 1994, 56:1215-1216.

37. Usami Y, Okamoto Y, Takayama T, Shigemasa Y, Minami S: Chitin and chitosan stimulate canine polymorphonuclear cells to release leukotriene B4 and prostaglandin E2. J Biomed Mater Res 1998, 42:517-522

38. Chevrier A, Hoemann CD, Sun J, Buschmann MD: Chitosan-glycerol phosphate/blood implants increase cell recruitment, transient vascularization and subchondral bone remodeling in drilled cartilage defects. Osteoarthritis Cartilage 2006, 15:316-327.

39. Barr ED, Pinchbeck GL, Clegg PD, Boyde A, Riggs CM: Post mortem evaluation of palmar osteochondral disease (traumatic osteochondrosis) of the metacarpo/metatarsophalangeal joint in thoroughbred racehorses. Equine Vet J 2009, 41:366-371.

40. Van Grevenhof EM, Ducro BJ, Van Weeren PR, Van Tartwijk JM, Van den Belt AJ, Bijma P: Prevalence of various radiographic manifestations of osteochondrosis and their correlations between and within joints in dutch warmblood horses. Equine Vet J 2009, 41:11-16.

41. Hunziker EB: Articular cartilage repair: are the intrinsic biological constraints undermining this process insuperable? Osteoarthritis Cartilage 1999, 7:15-28.

42. Shortkroff S, Barone L, Hsu HP, Wrenn C, Gagne T, Chi T, Breinan H, Minas T, Sledge CB, Tubo R, Spector M: Healing of chondral and osteochondral defects in a canine model: the role of cultured chondrocytes in regeneration of articular cartilage. Biomaterials 1996, 17:147-154.

43. Frisbie DD, Morisset S, Ho CP, Rodkey WG, Steadman JR, Mcllwraith CW: Effects of calcified cartilage on healing of chondral defects treated with microfracture in horses. Am J Sports Med 2006, 34:1824-1831.

44. Frisbie DD, Lu Y, Kawcak CE, DiCarlo EF, Binette F, Mcllwraith CW: In vivo evaluation of autologous cartilage fragment-loaded scaffolds implanted into equine articular defects and compared with autologous chondrocyte implantation. Am J Sports Med 2009, 37(Suppl 1):71S-80S.

45. Vacanti CA, Langer R, Schloo B, Vacanti JP: Synthetic polymers seeded with chondrocytes provide a template for new cartilage formation. Plast Reconstr Surg 1991, 88:753-759.

46. Brittberg M, Lindahl A, Nilsson A, Ohlsson C, Isaksson O, Peterson L: Treatment of deep cartilage defects in the knee with autologous chondrocyte transplantation. N Engl J Med 1994, 331:889-895.

doi:10.1186/s12917-014-0197-4

Cite this article as: Martins et al.: Evaluation of chitosan-GP hydrogel biocompatibility in osteochondral defects: an experimental approach BMC Veterinary Research 2014 10:197. 